\title{
Reaktualizacija besedilnih vzorcev v radijskih oglasih
}

\author{
Irena Stramljič Breznik
}

\begin{abstract}
Prispevek obravnava tip radijskih oglasov, v katerih je mogoče opaziti prvine medbesedilnosti, ki jo lahko razložimo kot vzajemno povezanost in odvisnost najmanj dveh besedil ali njihovih delov. Predstavljeni radijski oglasi so strukturirani kot posnetki ali imitacije znanih besedil tako, da so iz referenčnih tekstov aktualizirana le ključna mesta, ki konkretizirajo oglaševani predmet ali storitev.
\end{abstract}

Ključne besede: oglaševanje, medbesedilnost, radijski oglasi, aktualizacija besedilnih vzorcev

\section{Reactualization of text patterns in broadcasted ads}

The paper deals with the type of radio ads in which the elements of intertextuality could be seen, which may be interpreted as a mutual connection and dependence of at least two texts or their parts. Radio ads are structured as copies or imitations of famous texts in a way that only the key sites from reference texts, which help to define the advertised product or service, are actualized.

Key words: advertising, intertextuality, radio ads, text pattern actualization

\section{Uvod}

0.1 Sodobno oglaševanje ${ }^{1}$ je kompleksen pojav, ki se vrašča v družbo na vseh ravneh posameznikovega življenja, in kot ugotavlja Korošec (Korošec 2005: 11), izpolnjuje velik del javnega komunikacijskega prostora vseh medijev, v tisku, na radiu in televiziji, vse pogosteje pa tudi na spletnih straneh.

Kot predmet analize sega na področja sociologije, psihologije, kulturologije, medijskih študij, ekonomije, filozofije, zgodovine in psihologije. V devetdesetih letih 20. stoletja pa je jezik oglasov postal predmet intenzivnejšega raziskovanja tudi slovenskih jezikoslovcev z vidika jezikovne zvrstnosti, stilistike, pravopisa, frazeologije in besedotvorja (Bokal 1996/97; Humar 2000; Korošec 2005; Stramljič Breznik 2006; Verovnik - Logar 2006; Černetič 2007; Stramljič Breznik idr. 2008). Družijo jih skupne ugotovitve, da se v oglaševalske namene uporabljajo vsa raz-

1 Prispevek je nastal v okviru raziskovalnega projekta J6-2238: Slovenski jezik v stiku evropskega podonavskega in alpskega prostora, ki ga financira Agencija RS za raziskovalno dejavnost. 
položljiva jezikovna sredstva, še zlasti tudi leksikalna, med katerimi opazno mesto zasedajo tudi priložnostne novotvorjenke in grafoderivati (Stramljič Breznik - Voršič 2009), ki so nosilci estetske, ekspresivne in intelektualne vloge ter odražajo vse večjo vizualizacijo oglasne komunikacije.

0.2 Večina domačih in tujih lingvističnih raziskav oglaševanja je osredinjena na značilnosti tiskanih oglasov (Starc 2009), ${ }^{2}$ kar je po svoje tudi razumljivo vsaj iz dveh razlogov. Prvi izhaja iz tiska kot najstarejšega klasičnega medija in drugi iz dostopnosti do gradiva. Tiskani oglasi so namreč $\mathrm{s}$ svojo pisno podobo (besedna in slikovna izrazna sredstva) takoj primerni za analizo in jezikovno interpretacijo v primerjavi s televizijskimi ali radijskimi, ki najprej zahtevajo besedni zapis vseh prvin.

Prispevek se tokrat omejuje na radijske oglase z namenom, da opozori na zanimiv, dokaj pogost in posledično opazen pojav t. i. besedilnega vzorčenja ki, kot kaže, ima utemeljitev prav v naravi radijskega medija.

\section{$1 \quad$ Radio kot medij}

1.1 Alenka Valh Lopert (2008: 49-50 po Granić 2006: 268) navaja eno izmed sicer različnih klasifikacij medijev, po kateri obstajajo stari ali klasični mediji, to so tiskani (knjige in periodika) ter elektronski (radio in televizija), nove pa predstavljajo splet, elektronska pošta in sms-sporočila. Pri tem je radio ocenjen kot sicer najhitrejši medij (Pivec 2005: 55), a hkrati tudi drugotno občilo, ki ima v primerjavi $\mathrm{s}$ televizijsko sliko in možnostjo večkratnega branja časopisa le izginjajoč glas.

Porast radijskih postaj, zlasti lokalnih in komercialnih, pa kaže, da je radio kot medij še zmeraj aktualen. Na to vplivajo naslednji dejavniki: (1) poslušanje radia je del množične kulture in je medij govora, pri čemer je poslušalec aktiven soudeleženec, saj si podobo/sliko poročane situacije ustvarja sam; (2) poslušajo ga ljudje različnih starosti; (3) radio omogoča identifikacijo s skupino in vključenost v družbo; (4) novice prenese hitreje od časopisa in televizije; (5) programsko je raznovrsten in sorazmerno lahko in hitro pokriva različna področja družbenega in zasebnega življenja prebivalcev; (6) ni drag medij (Valh Lopert 2008: 50 po Zgrabljić Rotar 2007: 22-23).

1.2 Kot povzema Polona Pivec (2009: 47) po vodilnem hrvaškem komunikologu in raziskovalcu elektronskih medijev Mariu Plenkoviću (1993: 156), je prednost radia pred tiskom in televizijo $\mathrm{v}$ tem, da najlažje vzpostavi dvosmerno komunikacijo, saj je poslušalec ne samo poslušalec, ampak tudi govorec. To namreč omogočajo kontaktne oddaje, pa tudi različne oblike vključenih izjav, ki so opazen del sodobnega radijskega programa. Osnovnemu radijskemu namenu, tj. prenosu informacij,

$2 \mathrm{~V}$ primerjavi z omenjeno avtorico uporabljam samo termin oglas, ker ga priznavata tako oglaševalska kot jezikoslovna stroka. Izraz reklama (Korošec 2005: 15) je vezan na vsakdanjo nestrokovno rabo in praktično predstavlja perlokucijsko moč oglasa - oglas dela, naredi reklamo. 
se je zelo zgodaj pridružila tudi nova dimenzija (pri nas šele po osamosvojitvi), to sta tržna zanimivost in konkurenčnost programa, kar je rojevalo nove in nove komercialne radijske postaje. Radio kot dostopen, uporaben in dovzeten medij (Pivec 2009: 49) lahko v trenutku posreduje informacije široki množici ljudi, čeprav nagovarja vsakega posameznika posebej.

\section{Radijsko oglaševanje}

2.1 Radio je bil že zelo kmalu prepoznan kot medij, ki omogoča hitro in učinkovito oglaševanje, čeprav njegov delež v oglaševalskem kolaču danes postopno upada. Na podlagi rezultatov raziskav lahko potrdimo, da se ta delež iz leta $\mathrm{v}$ leto manjša in ga je prehitel celo splet, ki postaja perspektivnejši medij oglaševanja. Po podatkih Mediane je namreč januarja 2010 bruto vrednost oglaševanja v slovenskih medijih znašala 36,5 milijona evrov, kar je za petino več kot v januarju 2009. Televiziji je pripadal 64-odstotni delež, tiskanim medijem pa 25 -odstotni. Najvišjo rast bruto vrednosti oglaševanja so glede na januar 2009 zabeležili pri časopisih $(53,6 \%)$, na televiziji $(31,9 \%)$, v vloženkah tiskanih medijev $(14,4 \%)$ in na internetu $(10,1 \%)$, medtem ko so največji padec doživeli kinematografi $(64,8 \%)$, revije $(7,8 \%)$ in priloge dnevnikov $(7,1 \%) .{ }^{3}$ Za radio je po podatkih Mediane za leto 2009 tržni delež znašal 4,3 \% in predvidevamo, da je tudi v letu 2010 vsaj enak, če ne celo nižji. ${ }^{4}$

2.2 In katere so značilnosti radijskega oglaševanja? Gre za tip medija, ki sicer nagovarja le glasovno, vendar ima možnost vključiti lokalni okus, kar poveča njegovo privlačnost in poslušnost. Na eni izmed spletnih strani lokalne radijske postaje lahko najdemo pod rubriko Oglaševalske možnosti samopriporočilni oglas z zagotovilom, da je oglaševanje na tem radiu najučinkovitejše in najugodnejše, ker se po ceni 30 -sekundnega radijskega oglasa uvršča v sam vrh med ugodnejšimi. S tem je zagotovljeno, da oglaševalec za svoj denar dobi kar največ in da ne preplača oglaševanja. Hkrati pa naniza še naslednje prednosti, ki jih radio ima in ga delajo edinstvenega:

- Radio je dnevni spremljevalec in ljudem najbolj dostopen medij. Poslušalci imajo možnost spremljanja programa od jutra do noči, pa tudi v tistih življenjskih položajih, v katerih drugi mediji niso učinkoviti. Radio je edini medij, ki ga lahko poslušalci spremljajo ob drugih opravilih. To je tudi razlog, da povprečen prebivalec Slovenije med vsemi mediji največ časa nameni poslušanju radia.

- Radio lahko neposredno pred potrošnikovo odločitvijo za nakup oddaja impulze, na primer na poti v trgovsko središče. Promocijske akcije, ki potekajo prek radia, skrbijo za usmerjen »store traffic «.

3 Pridobljeno 14. 5. 2010 na spletni strani http://www.marketingmagazin.si/novice/v-januarju-za-petino-vecji-oglasevalski-kolac/.

4 Pridobljeno 14. 5. 2010 na spletni strani http://www.marketingmagazin.si. 
- Radio omogoča aktualnost, saj je oglaševalske akcije zanj možno razviti in izpeljati v kratkem času. Oglaševanje je tako fleksibilno in optimalno.

- Radijsko oglaševanje je lahko stimulativno, saj v kombinaciji s televizijskim prikliče določene asociacije in predstave tudi z akustičnimi dražljaji. S tem je učinkovitost oglaševanja znatno povečana v primerjavi s samo televizijskim oglaševanjem, saj akcija doseže širši spekter ciljne publike.

- Primerjalne študije dokazujejo, da radijski medij ob ugodnejši ceni doseže več potrošnikov. Produkcijski stroški radijskih oglasov so v primerjavi s produkcijskimi stroški tiskanih ali televizijskih bistveno nižji.

- Radio zaradi številnih ponovitev v različnih delih programa omogoča hitro širitev prepoznavnosti in učinkovito širjenje blagovne znamke.

- Televizijskega pojava hitrega preklapljanja različnih postaj, imenovanega »zapping«, pri radiu praktično ni.

- Radijski poslušalec dnevno v povprečju posluša le 1,5 različne radijske postaje, to pa pomeni, da je navezanost na neko postajo mnogo izrazitejša kot pri televiziji. ${ }^{5}$

Na nekatere tipične značilnosti radijskega oglaševanja je opozoril že Tomo Korošec (2005: 93-100). Izpostavil je bistveno lastnost radia, ki je omejen samo na slušnost. Ker ima omejeno možnost izrabe pribesedilnih prvin, jih nadomešča z dovršenim izborom jezikovnih sredstev, tj. govorom in dvogovorom, s pritegnitvijo različnih jezikovnih zvrsti in tujejezičnih prvin. Med pribesedilnimi prvinami uporablja predvsem glasbo in zvočne kulise. Tako vidno predstavo prepušča naslovniku, s čimer ga vključi v sporočanjski proces, zato je pritegovalni učinek oglasnega sporočila večji.

\section{Medbesedilnost $\mathbf{v}$ radijskih oglasih}

3.1 Oglasi so besedila, za katera je značilna pozivna funkcija (Hudej 2002: 62). $\mathrm{V}$ takih besedilih skuša tvorec od naslovnika doseči, da bi nekaj naredil, ravnal na določen način ali opravil neko dejanje. Moč posameznih argumentov odloča o uspešnosti ali neuspešnosti pozivnega besedila, izvira pa iz njihove prepričljivosti v konkretnih sporazumevalnih okoliščinah. Tvorec, ki želi, da bi se njegov namen zagotovo uresničil, mora izbrati sredstva, s katerimi pridobi naslovnikovo pozornost, vzbudi željo, ustvari potrebo, vzpodbudi naslovnika za dejanje, ki je v korist tvorcu.

Sonja Hudej (2001: 214-215) poudarja, da je argumentiranje s stališča besediloslovja prepričevanje, ki se lahko realizira na dva načina, in sicer kot utemeljevanje in kot pregovarjanje (manipulativni vzorec argumentacije). Utemeljevanje poteka s pomočjo pravilnih, dovolj močnih, sprejemljivih in relevantnih argumentov. Argumenti so v tem primeru sredstva racionalnega prepričevanja. Pri pregovarjanju pa so argumenti oblikovani tako, da preprečujejo naslovnikovo razumsko razmišljanje. Preračunani so na vrednote, interese, naslovnikove potrebe, želje in razpo- 
loženjska stanja; okrepljena čustva začasno odrinejo razum, dvome, vprašanja. Pri tem načinu nad racionalnimi prevladajo čustveni argumenti, oblikovani s stilistično izbiro izrazja ter z retoričnimi taktikami. Pregovarjanje poteka z vplivanjem na naslovnikova čustva; s sklicevanjem na vrednote, potrebe, želje; z močjo cenjenih avtoritet; s sklicevanjem na znanstvene izsledke; s prirejenimi zgledi oz. poskusi; z opogumljanjem naslovnika, naj si privošči, uživa, kupi.

3.2 Tvorec oglasa torej vnaprej premišljeno izbere prepričljiva jezikovna sredstva, ki bodo zbudila naslovnikovo pozornost, saj je le-ta temeljni pogoj za želen odziv. V naboru tovrstnih strategij ima zagotovo vidno mesto izraba znanih besedilnih vzorcev v oglaševalske namene.

Jezikoslovni pristop, zlasti v besediloslovju (de Beaugrande - Dressler 1992: 18), označuje medbesedilnost kot odvisnost tvorjenja in sprejemanja danega besedila od seznanjenosti udeležencev v komunikaciji z drugimi besedili. Gre za način rabe dobro znanih besedil in za sklicevanja na njih. Načeloma se lahko tvorec besedila sklicuje na vsako poljubno dosegljivo prejšnje besedilo, v praksi pa so primernejša dobro znana besedila, ker so prejemnikom lažje dostopna. Časovni interval med trenutkom tvorjenja izvirnega besedila in trenutkom tvorjenja naslednjega besedila se lahko močno spreminja (de Beaugrande - Dressler 1992: 128).

3.3 Za natančno analizo medbesedilnosti v oglasih pa je smiselno izhajati tudi iz teoretičnih temeljev medbesedilnosti v literarni vedi. Sredi šestdesetih let 20. stoletja se je namreč termin medbesedilnost (intertekstualnost) pojavil kot nov, moderni in mejni pojem, ki se je oblikoval v meddisciplinarni interakciji literarne vede, semiotike, lingvistike, psihoanalize, matematike, logike in filozofije (Juvan 2000: 5-11). Najbolj se je uveljavil v literarni teoriji, literarni hermenevtiki in teoriji recepcije, v katerih je sooblikoval nove poglede na literaturo in njeno specifičnost, na naravo ustvarjanja, na obstoj, smisel, tematiko, zgradbo in zvrstnost besedila, predvsem pa na vloge avtorja in bralca.

Termin medbesedilnost tako pomeni razmerje med besedili, njihov preplet, vpletenost enega besedila $\mathrm{v}$ drugem, vzajemno povezanost in odvisnost najmanj dveh besedil ali njihovih delov. Različni teoretiki ločujejo med občo in posebno medbesedilnostjo, ki sta poimenovani tudi implicitna in eksplicitna, specifična in univerzalna. Gre za ožje in širše razumevanje termina. Posebna medbesedilnost izhaja iz omejitve, da je medbesedilnost le domena literature in da naj bi jo izkazovala samo nekatera besedila, literarne zvrsti, žanri ali stili, drugod pa naj bi bila nerazvidna ali nerelevantna. Obča medbesedilnost pa je razumljena kot lastnost vseh besedil. Ni le privilegij književnosti, nekaterih njenih zvrsti ali del.

Pojem medbesedilnost tako implicira, da je besedilo replika na referenčno besedilo, s katerim tvori medbesedilni par, je z njim v vrednostni, pomenski, oblikovni in zvrstni soodvisnosti ter se vključuje z njim v množico besedil. Za potrebe medbesedilnega navezovanja se avtorji poslužujejo raznovrstnih tradicionalnih, ustaljenih medbesedilnih povezav, med katerimi so najpogostejše: parafraza, citat, aluzija in imitacija. 
3.4 Poseben tip medbesedilnega sklicevanja so medbesedilni posnetki ali imitacije, pri katerih novo besedilo deluje analogno predlogi, vendar je posneti vzorec postavljen $\mathrm{v}$ drugačno perspektivo in se mu s tem spremenita tudi smisel in funkcija (Juvan 2000: 259).

Opazovanje oglasov z vidika medbesedilnih prvin ponuja raznovrstne možnosti odkrivanja referenc, vgrajenih v njihovo strukturo, na različnih ravneh, in sicer na ravni jezikovnih sredstev (frazemi in pregovori v izhodiščni in prenovljeni podobi (Jerič 2002; Kržišnik 2006: 259-279; Černetič 2007: 377-394)), na ravni besedila (izsek dela znanega besedila, značilni elementi besedila določene funkcijske zvrsti) oz. besedilnega vzorca (izraba celotnega besedilnega vzorca določene funkcijske zvrsti ali standardiziranega obrazca).

V nadaljevanju so predstavljeni zanimivejši radijski oglasi, ki po Koroščevi tipologiji (Korošec 2005: 87) predstavljajo poleg prodajnih storitvenih še tip predstavitvenih, in sicer t. i. samopriporočilnih. Kot najpogostejši obliki medbesedilnega navezovanja $\mathrm{v}$ izbranih oglasih nastopata posnetek (imitacija) navadno enega, lahko tudi več besedil hkrati in primer vključitve citata.

\section{$4 \quad$ Imitacija ustaljenih besedilnih vzorcev in prvine citatnosti v oglasih}

4.1 Imitacijo lahko pomensko opredelimo kot posnetek oz. ponaredek. V literarnoteoretičnem smislu (Juvan 2000: 33) posnetek dovoljuje, da se avtor drži le nekaterih splošnih namigov originala in mu doda marsikaj svojega. Lahko variira besede in smisel izvirnika ali se obojemu celo odpove.

$\mathrm{V}$ tako oblikovanih oglasih besedilno okolje naslovnikovo pozornost najprej pritegne, nato pa od njega zahteva, da mu na podlagi spremenjenih prvin določi pomen in ga razume. V oglasih malokdaj pride do nerazumevanja povezave, saj se oglaševalci trudijo, da bi bili oglasi dostopni najširšemu krogu ljudi. Predloge lahko nastopajo na več ravneh, predstavljeni zgledi kažejo besedilno raven, kjer se na novo aktualizirajo znani in ustaljeni besedilni vzorci.

$\mathrm{V}$ oglasih je lahko prisoten tudi citat, ki je izražena in nespremenjena ponovitev večjega ali manjšega besedilnega dela (Kmecl 1996: 11-13). V analiziranem vzorcu citat obsega dobesedno navajanje poslovenjenega latinskega rekla.

4.2 V farmacevtski industriji so zelo agresivni oglaševalci, ${ }^{6} \mathrm{ki}$ za to dejavnost porabljajo veliko sredstev, saj v medijih zakupijo najbolj gledane ali poslušane termine. Tako je npr. na komercialni televizijski postaji POP TV v času od 19.00 do 20.00 v povprečju mogoče zaslediti do šest oglasov za prosto dostopna plačljiva farmacevtska sredstva (vitaminski, imunski pripravki, mazila za sklepe, sirup proti kašlju, protibolečinske tablete itd.).

6 Po podatkih imajo v oglaševalskem kolaču navišji delež farmacevtski izdelki in osebni avtomobili. Pridobljeno 14. 5. 2010 na spletni strani http://www.finance.si. 
Ob koncu jih vselej spremlja napisano in prebrano priporočilo, ki ga je mogoče šteti med oglaševalske avtomatizme (Korošec1998: 13-29; Verovnik - Logar 2006: 750): Pred uporabo natančno preberite navodilo. O tveganju in neželenih stranskih učinkih se posvetujte z zdravnikom ali farmacevtom. ${ }^{7}$ Pogosto ponavljanje tako vpliva na splošno zapomnljivost tega besedila, zato ga oglaševalci posnemajo in tako rekoč reaktualizirajo, kot potrjujejo naslednji zgledi. ${ }^{8}$

4.2.1 Oglas za osvežilno, brezalkoholno pijačo Fruc (dosegljiv tudi na spletu):

Pred uporabo ni potrebno ničesar natančno prebrati. O učinku in želenih učinkih se lahko posvetujete s prodajalcem ali natakarjem. Ta napitek je na voljo brez recepta in vam ne bo pomagal pri vnetju srednjega ušesa. Za več informacij o pravilni rabi obiščite www.fruc.si.

Referenčno besedilo je $\mathrm{v}$ oglasu modificirano na tehle ključnih mestih: na ravni negacije in naklonskosti dejanja (ni treba ničesar natančno prebrati; lahko posvetujete), stopnjevanju in nasprotnem poudarjanju samo pozitivnega vpliva rezultata dejanja (o učinku in želenih učinkih), aktualizacija živega delovalnika (prodajalec ali natakar), dodano pa mu je še standardizirano priporočilo o dostopnosti brez recepta, toda znova s presenetljivo negacijo dejanja (ne bo pomagal). Prepoznan besedilni vzorec je prenovljen na točkah, ki so opazne, in na način, ki zbuja pozornost, ker odstopa od pričakovanega.

4.2.2 Oglas komercialne radijske postaje Radio City za njihovo priljubljeno oddajo Reporter Milan je takle:

Znanstvene raziskave kažejo, da pomanjkanje smeha za 94 odstotkov poveča
možnost okužbe z izgubo smisla za humor, ki je danes edini mehanizem, ki
vaše telo učinkovito ščiti pred živčnim krahom. Zato priporočamo redni dnevni
odmerek Reporterja Milana, ki je garantirano brez škodljivih gensko modifici-
ranih organizmov. Reporter Milan. Zdrav duh v zdravem telesu. O tveganju in
neželenih učinkih se ne posvetujte z zdravnico ali farmacevtko.

Oglas uporablja tehniko prepričevanja, oprto na argumentacijo preverljivih in zanesljivih podatkov (znanstvene raziskave kažejo, številski podatek 94 odstot$k o v$ ), ki namiguje na značilnosti strokovnih besedil. Nepričakovan obrat predstavlja uporaba netipičnih leksemov na izpostavljenih delih besedila. V referenčnem strokovnem tekstu je namreč na tem mestu pričakovano pomanjkanje snovi, kot so npr. vitamini, minerali ipd., na posnetku pa ga nadomešča smeh, ki poveča možnost okužbe z izgubo smisla za humor (ne morda okužbe npr. dihal) in rešuje pred živčnim krahom. Opazna in presenetljiva je nova sopojavnica ob pridevniku živčni,

7 Prepis sledi izvirnemu besedilu, v tem primeru brez nezveneče variante predloga $s$ farmacevtom; obstajajo namreč tudi zapisi z njim.

8 Za pomoč pri zbiranju oglasov se iskreno zahvaljujem dr. Poloni Pivec (Radio Maribor), uredniku Boru Greinerju (Radio City) in novinarki Luciji Šolinič (Radio Celje). 
tj. krah. Prvič zato, ker je prvina po SSKJ nižje pogovorna s pomenom 'neuspeh, polom' in kot taka netipična $\mathrm{v}$ besedilnem okolju, ki namiguje na tip strokovnega besedila. Po drugi strani pa sta njeni tipičnejši pridevniški sopojavnici v slovarskem ponazarjalnem gradivu finančni in moralni, ki se pojavljata visoko na lestvici pomensko povezanih besed, preverjeno z uporabo statističnih metod korpusa Fidaplus (finančen na 10., moralnopolitičen na 12. in popoln na 23. mestu).

Sledi priporočilo za odmerek zdravila, ki je tokrat aktualiziran z naslovom oddaje (Reporter Milan), s katerim jamčijo, da je brez škodljivih gensko modificiranih organizmov. Besedna zveza namiguje na področje genskega inženiringa in na danes precej odklonilnih stališč do njega. Sledi citat poslovenjene oblike latinskega rekla (Zdrav duh v zdravem telesu) in zaključek s priporočilom, ki vsebuje dve modifikaciji: negacijsko (ne posvetujete) in ženskospolsko, zazanamovano različico ( $z$ zdravnico ali farmacevtko), najverjetneje uporabljeno kot nasprotje naslovu oddaje, $\mathrm{v}$ kateri nastopajo samo moški.

4.2.3 Radijski oglas Nostalgin Radia Celje gradi na kombinaciji dveh oglasnih besedilnih vzorcev, saj izhaja iz priporočila zdravnika in odziva naključnega uporabnika (kot npr. v primerih tv-oglasov za Actimel ali različne zobne paste) ter že omenjenega avtomatizma iz oglasov za farmacevtske izdelke. Priporočilo za svojo oddajo, $v$ kateri se vrtijo vedno zelene melodije, ki zbujajo nostalgijo po starih časih, gradijo na postopku medmedijske reaktualizacije oglasnega besedilnega vzorca:

Sem zdravnica Reiker. Kot učinkovito sredstvo proti stresu priporočam pilulo Nostalgin. Uživa se jo enkrat na teden, najbolje vsako sredo med peto in deveto uro. Ni mus, da na tě̌če. A veste, ste lahko tudi siti. Izboljšuje prebavo in blagodejno vpliva na vaše počutje.

Zunanji glas: Poglejmo, kaj pravi naključno izbrana ženska, ki danes brez Nostalgina praktično ne more več:

Moje počutje se je zelo izboljšalo, še več, odkar jemljem Nostalgin so se mi začeli vračati prelepi spomini in nimam več težav s prebujanjem. Zdaj se brez težav ob sredah zbudim ob petih, vzamem Nostalgin, ki učinkuje do devetih. Počutim se res odlično.

Zunanji glas: Pri uporabi natančno poslušajte glasbo. O tveganju in neželenih stranskih učinkih se posvetujte z zdravnikom ali farmacevtom in priporočajte Nostalgin.

V oglas so vključeni strokovnjak (zdravnica), »naključno izbran uporabnik«, kar je pogosta prvina televizijskih oglasov, in zunanji ženski glas (Korošec 2005: 7: vnanji), ki napove uporabnico in sklepno besedilo oglasa. Zdravnica priporoča jemanje zdravila Nostalgin, povezanega $\mathrm{z}$ naslovom oddaje, $\mathrm{v}$ terminu, ki ustreza njenemu predvajanju. Uporabi prvino pogovornega jezika (ni mus 'ni nujno') in dvoumnosti, ker lahko sitost razumemo v prenesenem (biti česa, koga (do grla, čez glavo) sit 'biti komu kaj odveč, nezaželeno') ali dobesednem pomenu, ki je utemeljen zaradi splošno znanega priporočila, da zdravil ne jemljemo na tešče. Uporab- 
nica aktualizira svoje dobro počutje s poslušanjem oddaje in ga zaključi z že kar ustaljeno izjavo uporabnika, pogosto slišano v podobnih tv-oglasih (Počutim se res odlično). Zaključek predstavlja za oglaševano radijsko oddajo prirejen končni del farmacevtskega opozorila, in sicer Pri uporabi natančno poslušajte glasbo (namesto Pred uporabo natančno preberite navodila). Sledi citat iz referenčnega besedila ( $O$ tveganju in neželenih stranskih učinkih se posvetujete z zdravnikom ali farmacevtom), ki mu je dodana nova sestavina (in priporočajte Nostalgin). S hitrejšim tempom ga prebere zunanji ženski glas.

4.2.4 Zanimiv je tudi oglas, ki je bil predvajan na Radiu Maribor in je vabil k vpisu gledaliških abonmajev, saj je uporabil besedilni vzorec oglaševanja, ki je sicer tipičen za turistične agencije.

Vroča »first minute« ponudba SNG Maribor v sezoni 2008/2009 ponuja umetniško potovanje na destinacije: drama, opera in balet, simfonični orkester in komorni koncert. Ne zamudite vpisa abonmajev SNG Maribor in zagotovite si svoj sedež na zemljevidih umetniških popotovanj skozi vso sezono.

Modifikacija besedila poteka na ravni sopojavnice, ki aktualizira oglaševano (umetniško, ne običajnejše turistično potovanje), destinacije, v običajnih turističnih oglasih zapolnjene s kraji potovanja ali letovanja, postanejo področja ponudbe SNG (drama, opera in balet, simfonični orkester in komorni koncert). Poziv ali apel (Korošec 2005: 85) dvakratno konkretizira gledališče (zagotovite si svoj sedež) in s sopojavnico (umetniških ob pojavnicah potovanje, potovanj).

4.2.5 Vabilni oglas Radia Maribor k aktivnemu kulturnemu udejstvovanju združuje modificiran opozorilni stavek, ki je avtomatizem pri oglaševanju alkohola: Ministrstvo za zdravje opozarja: prekomerno pitje alkohola škoduje zdravju v kombinaciji z že omenjenim framacevtskim opozorilom:

Oddelek za kulturo opozorja: umetnost lahko lajša življenjske bolečine, umetnost lahko lajša življenjske bolečine.

Pred uporabo natančno sledite svoji intuiciji, o tveganju, pomanjkanju ali neželenih učinkih se obrnite na najbližjo kulturno ustanovo. Ali pa začnite ustvarjati sami.

Znana besedilna vzorca sta prenovljena na nasprotnosti, in sicer negativno (pitje alkohola škoduje zdravju) - pozitivno (umetnost lahko lajša življenjske bolečine), razum (natančno preberite navodila) - čustvo (sledite svoji intuiciji). Pridružena je še ponovitev kot tipičen vzorec radijskega oglaševanja, saj se poved (umetnost lahko lajša življenjske bolečine) dvakrat ponovi, drugič je izgovorjena s počasnejšim tempom. Aktualizacija se zgodi na ravni delovalnika (zdravnik ali farmacevt), ki je konkretiziran z najbližjo kulturno ustanovo. Temu je dodan še poziv Ali pa začnite ustvarjati sami. 
4.2.6 Zadnja dva oglasa Radia Maribor izkoriščata komunikacijski vzorec s sodišča. (1) Prvi simulira in modificira dvogovor med pričo in sodnikom za potrebe najcenejšega nakupa $\mathrm{v}$ trgovini Tuš:

\author{
Sodnik: Priča je dolžna govoriti resnico in ne sme ničesar zamolčati. Za krivo \\ izpoved ste lahko kaznovani. \\ Priča: Razumem, gospod sodnik. \\ Sodnik: Ali je res, da ste v trgovini Tuš kupili pijačo Fanta Line light, liter in \\ pol za samo 228 tolarjev? \\ Priča: Res je. \\ Sodnik: Primer najcenejšega nakupa v Sloveniji je s tem dokazan. Razprava \\ je zaključena. \\ Zunanji moški glas izreče slogan: Tuš - dokazano najcenejši v Sloveniji.
}

(2) Drugi le povzema ugotovitveni vzorec iz prvega:

Sodnik: Primer najcenejšega nakupa v Sloveniji je dokazan. (Udarec s sodniškim kladivom kot znak za konec zasedanja sodišča.) Razprava je zaključena.

Zunanji glas izreče slogan: Tuš - dokazano najcenejši.

V dvogovoru sta uporabljena moški in ženski glas, ki omogočata večjo preglednost v dvogovoru. Presenetljivost zbuja banalnost položaja, saj mora priča pod prisego potrditi, da je bil nakup določenega izdelka v trgovini Tuš najcenejši, iz česar je izpeljan slogan Tuš - dokazano najcenejši $i$.

\title{
$5 \quad$ Sklep
}

Medbesedilnost je pomembna sestavina pri ustvarjanju oglaševalskih sporočil. Posamezne leksikalne prvine ali kar ustaljeni besedilni vzorci iz drugih komunikacijskih položajev prinašajo svoj izhodiščni pomen, ki je v oglasnem besedilu posneman in preoblikovan tako, da so prvine iz predloge zamenjane s takimi, ki konkretizirajo oglaševani predmet ali oglaševano storitev. Ker radio lahko uporablja samo slušni kanal, je to zanj pomembna bližnjica pri zbujanju naslovnikove pozornosti, ki je tako spodbujen, da vzpostavlja povezave, išče izvorne predloge in se aktivno vključuje v interpretacijo oglasnih sporočil. Reprodukcija besedil ali njihovih delov z ustrezno leksikalno in sintaktično prilagoditvijo za potrebe konkretnega oglasa zato predstavlja uspešno strategijo. Tvorci oglasnih besedil ne vlagajo energije v nastanek izvirnega besedila, ampak ustvarjalni potencial usmerijo na točke znanega besedila, v katerem smiselno aktualizirajo namen oglasa. Takšno besedilo sicer ni unikatno, toda zaradi prepoznavnega in osveženega modela zelo hitro doseže identifikacijo z naslovnikom (ker tvorec in naslovnik delita skupno prepoznavanje besedilnega vzorca) in hkrati pritegne njegovo pozornost, radovednost, ker prihaja do sporočanja nove (oglasne) vsebine, ki ni tipična za uporabljeni besedilni vzorec. V predstavljenih primerih radijskih oglasov je med drugim opazna tudi zanimiva reaktualizacija lastnih oglaševalskih avtomatizmov, ki imajo lahko celo značaj parodije. 
Sodobna oglaševalska komunikacija prek imitacij besedilnih vzorcev in $\mathrm{z}$ uporabo citatov v predstavljenih radijskih oglasih uspešno izrablja strategijo vzorčenja ali modeliranja, zato je v takih primerih upravičena ugotovitev, da so nekateri oglasi nova besedila v starem besedilnem vzorcu.

\section{Literatura}

de Beaugrande in Dessler 1992 = Robert de Beaugrande - Wolfgang Dressler, Uvod v besediloslovje, prev. Tjaša Miklič, Ljubljana: Park, 1992.

Bokal 1996/79 = Ljudmila Bokal, Jezik oglaševalskih besedil, Slava: debatni list 1996/97, št. 2, 125-126.

Černetič 2007 = Marinka Černetič, Vloga in značilnosti frazemov v slovenskih tiskanih oglasih, v: Frazeologija v jezikoslovju in drugih vedah, ur. Erika Kržišnik - Wolfgang Eismann, Ljubljana: Filozofska fakulteta, Oddelek za slovenistiko, 2007, 377-394.

Hudej 2001 = Sonja Hudej, Argumentacijski procesi in prepričevalna sredstva $\mathrm{V}$ besedilu, Slavistična revija 49 (2001), št. 3, 204-222.

Hudej 2002 = Sonja Hudej, Uspešnost uresničevanja tvorčevega namena v šestih besedilnih vrstah, Slavistična revija 50 (2002), št. 1, 61-81.

Humar 2000 = Marjeta Humar, Besedilne in jezikovne značilnosti reklamnih besedil, v: Kultura, identiteta in jezik v procesih evropske integracije, ur. Inka Štrukelj, Ljubljana: Društvo za uporabno jezikoslovje Slovenije, 2000, 315336.

Jerič 2002 = Marinka Jerič, Značilnosti in vloga frazemov v slovenskih tiskanih reklamah: diplomska naloga, Maribor: Pedagoška fakulteta, Oddelek za slovanske jezike in književnosti, 2002.

Juvan 2000 = Marko Juvan, Intertekstualnost, Ljubljana: DZS, 2000.

Kmecl 1996 = Matjaž Kmecl, Mala literarna teorija, Ljubljana: Mihelač in Nešović, ${ }^{4} 1996$.

Korošec 1998 = Tomo Korošec, Stilistika slovenskega poročevalstva, Ljubljana: Kmečki glas, 1998.

Korošec 2005 = Tomo Korošec, Jezik in stil oglaševanja, Ljubljana: FDV, 2005.

Kržišnik 2006 = Erika Kržišnik, Izraba semantične potence frazemov, v: Slovensko jezikoslovje danes, ur. Ada Vidovič Muha, Slavistična revija 54 (2006), posebna številka, 259-279.

Pivec 2005 = Polona Pivec, Dober javni radio ni samo zabava, v: Spominčice, ur. Stane Kocutar, Maribor: RTV Slovenija, Regionalni center, Radio, 2005.

Pivec 2009 = Polona Pivec, Novi jezikovni in pragmatični model kratkih radijskih informativnih besedil: doktorska disertacija, Filozofska fakulteta: Oddelek za slovanske jezike in književnosti, Maribor.

Plenković 1993 = Mario Plenković, Komunikologija masovnih medija, Zagreb: Barbat, 1993.

Starc 2009 = Sonja Starc, Časopisna oglaševalska besedila, reklame: struktura in večkodnost, Koper: Založba Annales, 2009. 
Stramljič Breznik 2006 = Irena Stramljič Breznik, Pravopisna norma v jeziku slikovnousmerjenih oglasov, v: Jezikovna predanost, ur. Marko Jesenšek - Zinka Zorko, Maribor: Slavistično društvo - Ljubljana: SAZU, 2006, 388-396.

Stramljič Breznik idr. 2008 = Irena Stramljič Breznik - Melita Zemljak Jontes - Simona Pulko - Alenka Valh Lopert - Mira Krajnc Ivič, Tako je bolje: priročnik z nasveti, kako odpraviti nekatere najpogostejše jezikovne težave v prodajnih katalogih trgovcev, Maribor: Filozofska fakulteta, Oddelek za slovanske jezike in književnosti, 2008.

Stramljič Breznik - Voršič 2009 = Irena Stramljič Breznik - Ines Voršič, Grafoderivati v tiskanih oglasih, Teorija in praksa 46 (2009), št. 6, 826-838.

Alenka Valh Lopert 2008 = Alenka Valh Lopert, Kultura govora v mariborskih medijih: nacionalni Radio Maribor in komercialni Radio City: doktorska disertacija, Filozofska fakulteta: Oddelek za slovanske jezike in književnosti, Maribor.

Verovnik - Logar 2006 = Tina Verovnik - Nataša Logar, O jeziku, stilu i utjecaju slovenskih tiskanih oglasa, v: Jagoda Granić, Jezik i mediji: jedan jezik - više svjetova: zbornik, Zagreb - Split: Hrvatsko društvo za primijenjenu lingvistiku, 2006, 743-752.

\section{Reactualization of text patterns in broadcasted ads}

Summary

The paper deals with the type of radio ads in which the elements of intertextuality could be seen and it might be interpreted as a reciprocal link or involvement of one text into another. Reproduction of texts or their parts with the appropriate lexical and syntactic adaptation for the needs of a particular ad represents an effective ad-making strategy. So there is no need to invest energy in the formation of new, original texts, but just to concentrate the creative potential to the points of already known text with logically update a regular ad. Such a text is not a unique one, but due to its recognizability and renew model, it reaches the identification with the recipient very quickly. It attracts the attention of audience as bringing a new advertised content not being typical of the used text pattern. 